\title{
Different Types of Minor Blood Group Incompatibility Causing Haemolytic Disease of Neonates in one of the National Children's Medical Centre in China
}

\author{
Mingchun Lin ${ }^{1,2}$ \\ Meixiu $\mathrm{Liu}^{3}$ \\ Shulian Zhang' \\ Chao Chen' \\ Jin Wang'
}

'Neonatal Department, Children's Hospital of Fudan University, Shanghai, 201 102, People's Republic of China; ${ }^{2}$ Neonatal Fellowship Training at Children's Hospital of Fudan University, Yueqing Maternal and Child Health Hospital, Wenzhou, Zhejiang Province, People's Republic of China; ${ }^{3}$ Blood Bank, Children's Hospital of Fudan University, Shanghai, 20I 102, People's Republic of China
Correspondence: Jin Wang Neonatal Department, Children's

Hospital of Fudan University, No. 399,

Wanyuan Road, Shanghai, 20II02,

People's Republic of China

Tel +86-2I-64932960

Email drwangjin@fudan.edu.cn
Purpose: To review the neonatal cases with different types of minor blood group incompatible haemolytic diseases in China, and to improve the clinical understanding and management.

Materials and Methods: Seven cases from January, 1st, 2013 to December 31st, 2019 were searched out and reviewed retrospectively. All clinical data and laboratory findings were collected.

Results: There were totally seven cases enrolled including three cases of MNS, three of Diego, and one of Kidd combined with $\mathrm{Rh}$, anti-RhE incompatibility. Among the seven cases, two had intrauterine transfusion, two underwent exchange transfusion, five received intravenous immune globulin, five cases developed anaemia, and three of them had transfusion. But among them, only four were found to have positive antibody screening and three were confirmed HDN with antibody types antenatally.

Conclusion: The clinical presentation is diverse. Antibody screening followed by the technique of peak systolic velocity in the fetal middle cerebral artery (MCA-PSV) helps to filter out the severe cases.

Keywords: neonatal haemolytic disease, HDN, alloimmunization, MNS blood group, Diego blood group, Kidd blood group

\section{Introduction}

Haemolytic disease of the newborn (HDN) refers to foetal or neonatal alloimmune haemolysis caused by red blood cell antibodies due to incompatible maternal and foetal or neonatal blood types. The prevalence varies according to blood type. ${ }^{1,2}$ $\mathrm{ABO}$ incompatibility is the most common cause of $\mathrm{HDN}^{3,5} \mathrm{Rh}(\mathrm{D})$ antigen is the second most common, and $\mathrm{Rh}(\mathrm{C}, \mathrm{c}, \mathrm{E}, \mathrm{e})$ antigen incompatibility occurs occasionally. $^{5-7}$ Several other alloantibodies have also been reported to be associated with haemolytic diseases, including MNS, Kidd, Diego, Duffy, Kell and Anti-Mur. ${ }^{9-14}$ However, most literatures on these diseases were published as case reports. Therefore, the presentation of the haemolytic diseases related to different minor blood group incompatibilities is not well understood. Here, a retrospective analysis of neonates with minor blood type haemolytic disease admitted to one medical centre over the past 6 years was conducted to improve awareness and perinatal management for Chinese population. 


\section{Materials and Methods}

This research topic was approved by institutional research ethics board of Children's Hospital of Fudan University. All cases were identified from the electronic database and met the inclusion criteria: newborns admitted to the neonatal department of Children's Hospital of Fudan University with a diagnosis of neonatal alloimmune haemolytic disease due to minor blood type incompatibility between January 1st, 2013, and Dec 31st, 2019. All the electronic information of these cases was reviewed to rule out single $\mathrm{ABO}$ or $\mathrm{Rh}$, including $\mathrm{D}, \mathrm{E}, \mathrm{e}, \mathrm{C}$, and $\mathrm{c}$ blood group incompatibility, as well as other reasons for haemolysis, such as G6PD and red blood cell membrane defects such as hereditary spherocytosis, as exclusion criteria. We obtained the written informed consents from the parents of all cases and got the permissions to have all the case details published.

The key diagnostic criteria were defined as serological tests showing positive Coombs' test and related blood group system antibodies detected in the serum of newborns and/or mothers. Other evidence of haemolysis, such as complete blood count, haemoglobin level, reticulocyte count, and serum bilirubin levels, were consistent with haemolytic disease. All the cases had the confirmed diagnostic tests done in Shanghai blood centre, and the blood samples were sent on admission or initially after birth. $\mathrm{ABO}$ and $\mathrm{RhD}$ blood typing tests were performed with the tube by standard methods for each sample, using monoclonal anti-A, anti-B and anti-D (Shanghai Blood Biomedicine Co., Ltd.). Other phenotypes of the red blood cells (RBCs) were determined using monoclonal anti-E, anti-C, anti-c, anti-e, anti-M, anti-N (Shanghai Blood Biomedicine Co., Ltd.), antiDia, anti-Dib, anti-JKa and anti-JKb antibodies (Sanquin Reagents B.V.) respectively. The spectrum cells used for blood group antibody identification were purchased from Shanghai Blood Biomedicine Co., Ltd. and Sanquin Reagents B.V. DAT (direct antiglobulin test) was performed with the tube using multispecific antiglobulin reagents, monospecific antibody-IgG, and monospecific antibody-C3d (Shanghai Blood Biomedicine Co., Ltd.). IAT (indirect anti-human globulin test, included free antibody test and antibody release test) was performed with the tube using multispecific antiglobulin reagents and column agglutination technique using gel cards (Bio-Rad Laboratories).

\section{Results}

\section{Data Collection and Summary}

A total of seven cases were finally enrolled, including three cases of MNS haemolytic disease, three cases of Diego incompatibility, and one case of Kidd combined with anti-RhE blood group incompatibility. All the electronic charts of the seven cases were reviewed and collected, including antenatal and postnatal information such as maternal history, birth history, gender, gestational age, laboratory tests including maternal and child blood types, blood cell count, haemoglobin level, reticulocytes, bilirubin, and Coombs test. Treatment data, including the use of phototherapy, IVIG, blood transfusion, or exchange transfusion, and outcomes were also collected. Phototherapy and exchange transfusion were managed referring to the criteria of the American Association of Paediatrics Clinical Practice Guideline for phototherapy and exchange transfusion in hospitalized infants of 35 or more weeks' gestation. $^{15}$

\section{Result}

A total of three different minor blood types were found to be associated with haemolytic disease in our search, including the MNS, Diego, and Kidd blood groups. We summarized all the cases in separate categories as follows (Table 1).

\section{Three Cases of MNS Haemolytic Disease}

Case 1 , a male born by caesarean section at $39^{+1}$ weeks with a birth weight of $3950 \mathrm{~g}$ to a healthy 32-year-old mother (G1P1), was admitted to our NICU on day 3 because of jaundice and anaemia from day 2 of life. Coombs' test was performed immediately according to the clinical presentation. DAT (direct agglutination test) was negative, but IAT (indirect antiglobulin test) was positive, and anti-M antibodies were detected in the newborn's serum. He received only phototherapy during the hospitalization period without blood transfusion because of no deterioration of haemoglobin afterward. This was the mother's first child, conceived through IVF, and the mother had an antibody screening result of anti-M and titres of 1:512 IgM and 1:256 IgG at 35 weeks gestation. All clinical characteristics are shown in Table 1.

Case 2, a male infant born by vaginal delivery at $37^{+6}$ weeks with a birth weight of $3000 \mathrm{~g}$ to a healthy 23-yearold mother (G2P2) was admitted to our NICU on day 4 because of jaundice from day 2 of life. Coombs' test was performed after admission to the patient with negative 


\begin{tabular}{|c|c|c|c|c|c|c|c|c|c|}
\hline \multirow{6}{*}{ 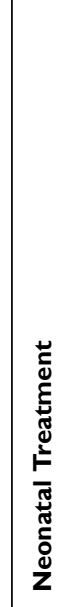 } & 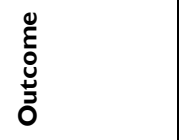 & 㞼 & $\stackrel{\bar{m}}{\stackrel{\bar{m}}{=}}$ & 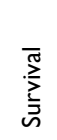 & 辝 & $\stackrel{\bar{m}}{\stackrel{\bar{m}}{\bar{s}}}$ & $\stackrel{\bar{m}}{\sum_{\bar{n}}^{\bar{n}}}$ & $\stackrel{\overline{3}}{\stackrel{5}{5}}$ & $\begin{array}{l}\ddot{\tilde{c}} \\
\stackrel{\overline{\underline{\omega}}}{\bar{\varepsilon}}\end{array}$ \\
\hline & $\underset{\substack{\text { qux } \\
\text { ux }}}{u}$ & $z$ & $z$ & $\succ$ & $z$ & $z$ & $\succ$ & $\succ$ & \\
\hline & $\stackrel{0}{\alpha}$ & $z$ & $z$ & $z$ & $\succ$ & $\succ$ & $z$ & $z$ & \\
\hline & $\stackrel{0}{\geq}$ & $z$ & $z$ & $\succ$ & $\succ$ & $\succ$ & $\succ$ & $\succ$ & \\
\hline & 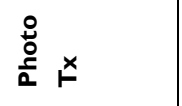 & $\succ$ & $\succ$ & $\succ$ & $\succ$ & $\succ$ & $\succ$ & $\succ$ & $\ddot{\vec{g}}$ \\
\hline & 离 $\underset{\vdash}{ }$ & $z$ & $z$ & $z$ & $z$ & z & $\succ$ & $\succ$ & \\
\hline & 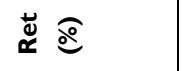 & ث̈ं & $\underline{m}$ & $\overline{0}$ & $\stackrel{\infty}{\infty}$ & กี & 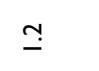 & $\stackrel{m}{*}$ & 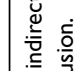 \\
\hline & 全 $\delta$ 安 离 & $a$ & 을 & $\underset{\sigma}{\sigma}$ & $\underset{\Xi}{\ddagger}$ & 今ે & in & 气 & \\
\hline & 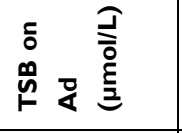 & $\stackrel{\text { Ln }}{\stackrel{\sim}{\sim}}$ & 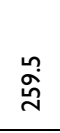 & $\hat{\underline{m}}$ & $\stackrel{\mathscr{\gamma}}{\%}$ & 命 & 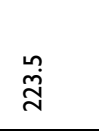 & 装 & \\
\hline & 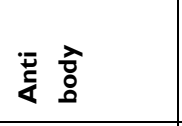 & $\begin{array}{l}\sum_{i=1} \\
\text { 立 } \\
\end{array}$ & 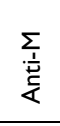 & 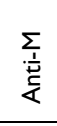 & 高 & 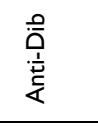 & 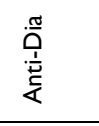 & 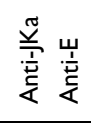 & $\stackrel{0}{;}$ \\
\hline & 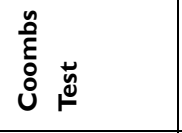 & 客 & 客 & 客 & & 旁荣 & $\frac{\sqrt{\frac{1}{4}}}{\frac{1}{\Delta}}+$ & 索索 & 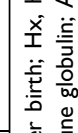 \\
\hline & ¿ & $\begin{array}{l}Z \\
\Sigma \\
+ \\
0\end{array}$ & $\begin{array}{l}Z \\
\sum \\
+ \\
+\end{array}$ & $\begin{array}{l}Z \\
\Sigma \\
0^{+}\end{array}$ & & 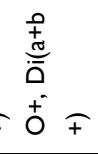 & 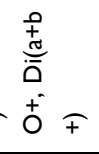 & 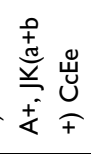 & 亮 \\
\hline के & 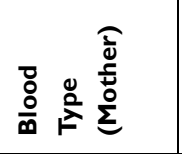 & $\begin{array}{l}z \\
z \\
\pm \\
\pm\end{array}$ & $\begin{array}{l}z \\
z \\
+ \\
0\end{array}$ & $\begin{array}{l}z \\
z \\
+ \\
+\end{array}$ & & 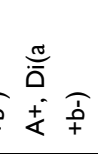 & 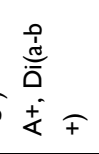 & 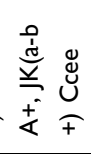 & 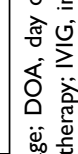 \\
\hline \multirow{2}{*}{ 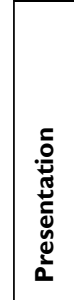 } & 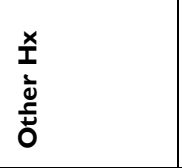 & 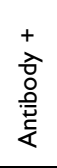 & $\overleftarrow{\mathbf{z}}$ & 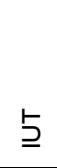 & $\begin{array}{l}\varangle \\
\frac{c}{\xi} \\
\end{array}$ & $\begin{array}{l}\infty \\
\frac{5}{3}\end{array}$ & 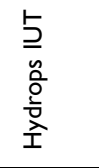 & 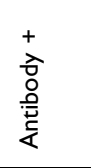 & 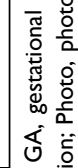 \\
\hline & 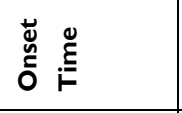 & $\stackrel{\sim}{\widehat{A}}$ & ลิ & बे & ๙ิ & $\stackrel{\sim}{\widehat{A}}$ & 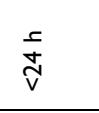 & 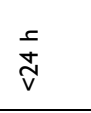 & 结 \\
\hline ઠ & & & 苍 & તิ̊ & 薟 & 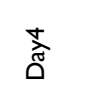 & $\bar{\AA}$ & 좀 & \\
\hline 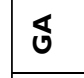 & & & $\hat{m}$ & $\stackrel{ \pm}{m}$ & $\hat{m}$ & $\hat{m}+$ & $\tilde{m} \mp$ & 㝏 + & \\
\hline ڤึ & & $\Sigma$ & $\Sigma$ & $\Sigma$ & $\Sigma$ & $\Sigma$ & $\Sigma$ & 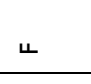 & \\
\hline हू & & & స్త్ & $\begin{array}{l}\overline{0} \\
\text { 㟢 }\end{array}$ & 苟 & 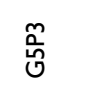 & $\underset{\mathcal{G}}{\tilde{q}}$ & స్ & \\
\hline 离 & & - & $N$ & $m$ & $\sigma$ & n & 0 & $r$ & \\
\hline
\end{tabular}


DAT and positive IAT, and anti-M antibodies were detected in the newborn's serum. He received phototherapy for treatment. This mother had received regular antenatal care during pregnancy, but no antibody screening test was performed. Her first child was a healthy four-yearold girl without a history of jaundice at birth.

Case 3, a male infant was admitted to our NICU on day 27 with a confirmed diagnosis of anti-M HDN at birth in a maternity hospital where he had positive IAT results and negative DAT results and received one blood transfusion, one IVIG and multiple phototherapies. Admission to our NICU was due to severe anaemia. Both DAT and IAT were negative, but the antibody screening test was positive for anti-M on day 27. A 2nd blood transfusion was given after this admission. This baby was a G5P1 preterm infant with a gestational age of $34^{+1}$ weeks and birth weight of 2345 $\mathrm{g}$ born by caesarean section due to MN-related HDFN in the foetus and elevated peak systolic velocity in the foetal middle cerebral artery (MCA-PSV) on ultrasound. ${ }^{16}$ This 33-year-old mother had a very complicated maternal history with four previous failed pregnancies, including one intrauterine demise and three spontaneous abortions, two of which were confirmed as foetal hydrops. This patient was gravida 5, and positive antibody screening with anti$\mathrm{M}$ was detected at 20 weeks gestation during this pregnancy. The foetus received intrauterine transfusion (IUT) twice with $\mathrm{O}$ RhD- and M-RBCs at 30 and $32^{+6}$ weeks gestation, respectively. Cordocentesis was performed during the first IUT, and allo-anti-M antibodies were eluted from the cord blood sample, which suggested MN-related HDFN in the foetus.

All three of these cases of MN blood type haemolytic disease have the same antibody type, which is anti-M. The MN blood types of the mothers and newborns were all the same, namely, MN for the mother and NN for the newborn. Jaundice occurred within the first two days in all three cases. The bilirubin levels were not very high because all the cases were sent from maternity hospitals, and phototherapy commenced as soon as jaundice was noted. Two of the newborns had different degrees of anaemia, and the haemoglobin trough values of cases 1 and 3 were as low as $93 \mathrm{~g} / \mathrm{L}$ and $49.2 \mathrm{~g} / \mathrm{L}$, respectively. In case 3 , the patient required two rounds of IUT and two rounds of RBC blood transfusion after birth, as well as IVIG, which is the most drastic therapy. Prenatal examination revealed positive antibody screening tests in two cases, and prenatal care follow-up of MCA-PSV helped to diagnose the most severe case (case 3).

\section{Three Cases of Diego Haemolytic Disease}

Case 4 and Case 5 were monochorionic diamniotic (MD) twins, born at a gestational age of $37^{+4}$ weeks, and both were admitted to our NICU on day 4. These two male newborns were G5P2 and G5P3 born by caesarean section with birth weights of $2700 \mathrm{~g}$ and $2200 \mathrm{~g}$ to a healthy 37-year-old mother. They were transferred because of severe jaundice from day 2 of life without anaemia and suspected haemolysis disease at a local hospital. G1P1 of this mother was a healthy girl without a history of jaundice during the newborn period, but the mother's other pregnancies were ended with induced labour twice and idiopathic spontaneous abortion once. She did not receive an antibody screening test during pregnancy. Coombs' tests were performed in the maternity hospital for the twins because of the early onset of jaundice. Both DAT tests were positive, but the laboratory could not confirm the antibody type. We sent all the blood samples of the mother and twins to the Shanghai Blood Centre to repeat the Coombs' tests, and positive results for both DAT and IAT were confirmed as antiDib. The mother's blood type was A+, Di(a+b-), and both twins had the same blood type, $\mathrm{O}+, \mathrm{Di}(\mathrm{a}+\mathrm{b}+)$. Both twins received IVIG, albumin and phototherapy as treatment. The initial planned blood exchange transfusion was cancelled due to the lack of $\mathrm{Di}(\mathrm{b}-)$ PRBC available on the first day, and the hyperbilirubinemia was well controlled afterwards.

Case 6, a preterm male newborn, was born to a 44-year -old mother $(\mathrm{G} 4 \mathrm{P} 2)$ at $32^{+1}$ weeks gestation by caesarean section because of suspecting foetal hydrops on ultrasound with a birth weight of $2380 \mathrm{~g}$. This foetus received intrauterine transfusion (IUT) six times from 24 weeks of gestational age until birth with O RhD-, Di(a-) RBCs after a confirmed maternal positive antibody test for anti-Dia and elevated peak systolic velocity in the foetal middle cerebral artery (MCA-PSV) on ultrasound. The mother was transferred from a local hospital because of positive antibody screening with unclear antibody type. The infant required CPAP support shortly after delivery due to neonatal respiratory distress syndrome (NRDS). He had no significant hydrops after full assessment at birth, but he had severe anaemia with a haemoglobin trough value as low as $57 \mathrm{~g} / \mathrm{L}$ when he was admitted to our NICU within 24 hours of life, decreased from $116 \mathrm{~g} / \mathrm{L}$ at birth. He was treated by blood exchange transfusion once after birth, three doses of IVIG, RBC transfusion once and multiple 
phototherapies. The mother had one healthy child and two idiopathic spontaneous abortions prior to this pregnancy.

These three cases (No. 4, 5, and 6) were all considered haemolytic disease due to Diego blood type incompatibility. The twins (Case 4 and 5) presented moderate to severe jaundice from day 2 and had peak total bilirubin levels of $430 \mu \mathrm{mol} / \mathrm{L}$ and $356.7 \mu \mathrm{mol} / \mathrm{L}$, respectively. However, just one of the twins had mild anaemia with a haemoglobin level of $144 \mathrm{~g} / \mathrm{L}$ and a reticular count of $8.8 \%$. In both cases, diagnosis was confirmed by positive DAT, IAT and anti-Dib antibody tests. The patients recovered with phototherapy, IVIG, and albumin transfusion. Case 6 was another case of haemolytic disease due to Diego incompatibility caused by anti-Dia antibody. This case presented severe HDFN from the beginning of the third trimester. Although the hyperbilirubinemia was not especially significant, with peak TSB at $223.5 \mu \mathrm{mol} / \mathrm{L}$ after birth, he had severe anaemia requiring exchange transfusion and red blood cell transfusion even after six IUTs.

\section{One Case of Haemolytic Disease Due to Combination Kidd and Rh Blood Group Incompatibility}

Case 7 , A female was born at $38^{+4}$ weeks by vaginal delivery to a healthy 28-year-old mother (G2P2). The mother's first child was a healthy boy with no jaundice at birth and an uneventful pregnancy. However, during this pregnancy, she had a positive result in an antibody screen at local hospital, without identification of the antibody type. She was referred to a tertiary hospital for antenatal care and delivery. The newborn experienced severe hyperbilirubinemia within 24 hours after birth, with peak bilirubin $444.2 \mu \mathrm{mol} / \mathrm{L}$ and minimum haemoglobin value 117 g/l. Coombs' tests performed by the Shanghai Blood Centre were positive for DAT and IAT, with positive anti-E and anti-JKa antibody screening and DAT/IAT. The diagnosis of combined antibodies also appears in other literature. ${ }^{17}$ Full treatments for HDN, including blood exchange, IVIG and phototherapy, were given.

All seven cases received formal Coombs tests for diagnosis at the Shanghai Blood Centre. The tests performed at hospital laboratories report positive DAT and/or IAT and positive antibody screening but do not confirm the blood type responsible for the haemolytic disease. Some of the mothers were transferred from local hospitals outside of Shanghai due to positive antibody screening in mother's serum with unclear antibody type (case 7). Antenatal diagnosis was performed in the Shanghai Blood Centre for some cases (cases 1, 3 and 6) on the bases of the maternal blood antibody screening tests.

All the cases enrolled presented different degrees of jaundice, and the haemoglobin level ranged between 49.2 and $207 \mathrm{~g} / \mathrm{L}$, which may reflect the variability of the severity of haemolysis. The sickest of the three cases of MNS blood type had IUT and severe anaemia, but the other two cases had only mild anaemia and moderate jaundice requiring phototherapy. The same occurred in Diego blood type.

It was also noticed that the MNS blood type cases all had positive IAT and negative DAT. Two patients who underwent IUT both had negative DAT results. However, another two cases of Diego incompatibility had positive DAT and IAT.

All seven patients improved and were discharged. All of them underwent brain MRI and BAEP before discharge to assess potential brain damage due to early hyperbilirubinemia and anaemia. Case 7 had abnormal MRI signals on the right parietal lobe and right caudate nucleus, which were diagnosed as cerebral infarctions of unclear cause. Case 3 and case 6, as preterm infants, had characteristics of prematurity on brain MRI. None of the infants had significant signs of bilirubin encephalopathy on MRI. The results of brain stem auditory evoked potential (BAEP) showed that case 1 failed on the left side with a hearing threshold of $45 \mathrm{~dB}$, and cases 6 and 7 failed on both sides with a mild degree of hearing loss. The remaining four infants passed this investigation before discharge. Cases 1, 6 and 7 passed the BAEP during follow-up. All seven cases were followed up at different ages. The oldest age of follow-up was three years for case 3; most of the other cases were followed up until two years of age. The shortest follow-up was for case 7, who was last seen at our clinic at 6 months of age. None of the patients required $\mathrm{RBC}$ transfusion after discharge, and some received iron supplementation. None of them presented long-term issues in hearing, motor development, or dental enamel, nor extrapyramidal symptoms or athetosis.

\section{Discussion \\ Discussion}

In China, HDN is most commonly caused by ABO blood group system incompatibility, followed by Rh blood group incompatibility. It has been reported that ABO HDN accounts for $85.3 \%$ and $\mathrm{Rh}$ accounts for much less than $14.6 \%$ of total cases in China. ${ }^{18}$ Other blood group system 
incompatibilities, such as MNS, Diego, and Kidd, are relatively rare. The prenatal discovery of haemolytic disease caused by minor blood group incompatibility is insufficient throughout China. The lack of confirmed antenatal diagnosis may present a challenge for neonatologists because the clinical severity of these entities varies. The clinical presentation and laboratory characteristics of $\mathrm{ABO}$ and Rh HDN are clear to most obstetricians and neonatologists, ${ }^{19-21}$ but this is not the case for all of these minor blood type HDNs. ${ }^{22}$ Consistent antenatal and postnatal management is important for both obstetricians and neonatologists. For early jaundice with positive Coombs test, either DAT or IAT, and unexplained antibody within the first few days, it is necessary to rule out all types of minor blood group haemolytic diseases.

We also noticed four cases with positive antibody screening during antenatal care in our cases. Antibody screening during pregnancy is encouraged for antenatal diagnosis. For pregnant women with positive results, further follow-up combined with determination of the peak systolic velocity of the foetal middle cerebral artery (MCA-PSV) on ultrasound is the protocol suggested to identify severe intrauterine haemolysis. ${ }^{23}$ As cases 3 and 6 in our study both benefited from this screening, and the mothers in both cases had had more than one idiopathic spontaneous abortion before in previous pregnancies, foetal death due to severe haemolysis could be the reason for the previous abortions. Severe haemolysis symptoms were noticed after positive antibody screening during the case pregnancies, and intrauterine transfusions (IUTs) were used for rescue. ${ }^{24}$ Even for cases without intrauterine interventions, antenatal screening is helpful for obstetricians and neonatologists to more carefully track the severity of haemolysis in the newborns, and early transfer or treatment could be performed, as in cases 1 and 7 . Therefore, antenatal screening is necessary for identifying severe cases and following intrauterine intervention. ${ }^{25}$

Anti-M antibody is the second most common non- $\mathrm{RhD}$ antibody identified in pregnant women, ${ }^{26}$ but it has not been considered an important cause of HDN, especially in Caucasian and black populations. ${ }^{8,27}$ The reason is that anti-M antibodies have been identified as naturally occurring antibodies, ${ }^{28}$ and both IgM and IgG anti-M antibodies have been reported in retrospective studies from American and Dutch populations, among others, ${ }^{8,29}$ with no cases of mild or severe HDN. In addition, anti-M has been found in the serum of individuals who have not been exposed to human erythrocytes. However, an increasing number of
HDN cases caused by anti-M have been reported, especially in Japanese, Chinese, and other Asian populations. ${ }^{30-32}$ Anti-M was the most common antibody in our study as well, and all cases were caused by the same anti-M antibody of the MNS blood group system. One case was the first pregnancy of the mother, and the other two cases were the second and fifth pregnancies, which is similar to the pattern observed for ABO HDN because anti-M antibodies can occur naturally. ${ }^{26}$ The severity of this HDN is quite variable, which has also been reported in previous studies. ${ }^{33,34}$ All cases were negative for DAT, which is different from other minor blood type and $\mathrm{Rh}$ HDNs. This is an important point to help clinicians to identify anti-M HDN, because most cases of HDN have positive DAT, except ABO HDNs. ${ }^{4}$ When the DAT is negative, most clinicians will rule out minor blood group haemolysis disease, and IAT of ABO will be conducted if the patient presents haemolysis, which may cause the misdiagnosis of anti-M haemolysis.

Therefore, we suggest that both DAT and IAT tests should be performed for all patients with suspected haemolysis disease. For the cases with positive DAT and IAT, it is better to identify the type of RBC antibody. As minor blood group haemolysis diseases are rare in the population, this full laboratory test with all blood type standard red blood cells is not economical to perform in all local hospitals, but it is necessary for one lab in an area to have the capability of identifying these antibodies so that rare samples can be sent for diagnosis. Another solution is to organize central blood centres equipped with laboratory technology for the determination of most minor blood group antibodies and a few tertiary medical centres that can perform antepartum treatments, such as intrauterine transfusion (IUT). Then, the pregnant woman would be able to be transferred upon suspicion of minor blood group incompatibility, as in some of our cases.

The remaining types, Diego ${ }^{35,36}$ and Kidd, ${ }^{37,38}$ presented typically with jaundice, anaemia after birth, and positive DAT and IAT, which helped make the confirmed diagnosis. The only case with negative DAT had multiple IUTs, which probably indicates that the laboratory results of foetal and neonatal blood type, DAT and IAT may be changed after IUTs.

Complex anti-E and JKa antibodies occurred in case 7, and the patient presented severe haemolysis symptoms requiring either exchange transfusion or red blood cell transfusion. In the laboratory results, the titres of the two types of antibodies were similar, and it is therefore 
difficult to identify which is the major cause. However, mixed antibodies from different blood types may make haemolysis symptoms more serious. ${ }^{17}$

The overall management for all seven cases in our project was routine clinical care, including bilirubin monitoring, phototherapy, exchange transfusion, IVIG, red blood cell transfusion, and evaluation of the central nervous system. ${ }^{15}$ Although the time of anaemia and hyporegeneration of erythroblasts varies, the severity of haemolysis could vary by type, and close monitoring and follow-up are necessary. All seven patients in this case series survived. This indicates that the management and follow-up for HDN is currently well performed in China, but early clarification of the diagnosis affects the management, which may help prevent early delivery or abortion and hydrops foetalis.

\section{Conclusion}

There are more than 30 types of minor blood type haemolysis disease, and we had 7 such cases, including three different blood types in one centre. The characteristics of these three types are variant, and we highlight that the antenatal antibody screening test is a simple first-line test for pregnant women. The examination of peak systolic velocity in the foetal middle cerebral artery (MCA-PSV) on ultrasound helps to identify severe cases. Full Coombs' test including both DAT and IAT for suspected neonates is necessary. It is not reliable to only check the DAT of Coombs' test for the diagnosis of minor blood group HDN since the DAT may be affected by the intrauterine intervention and negative for MNS haemolysis. Access to an unhindered regional transfer system for blood samples and patients in serious cases is necessary for sites without full diagnostic capability. Clear alloantibody typing results are important for preparing exchange transfusions and/or red blood cell (RBC) transfusions in serious cases and follow-up.

\section{Author Contributions}

Lin Mingchun: acquisition and analysis of data, drafting the article.

Liu Meixiu: data curation and analysis.

Zhang Shulian: data curation, interpretation of data.

Chen Chao: final approval of the version.

Wang Jin: design of the study, revising and final approval of the draft.

All authors contributed to the article have agreed on the journal to which the article will be submitted, gave final approval of the version to be published, and agree to be accountable for all aspects of the work.

\section{Funding}

This research did not receive any specific grant from funding agencies in the public, commercial, or not-forprofit sectors.

\section{Disclosure}

All the authors have disclosed no conflicts of interest.

\section{References}

1. de Haas M, Thurik FF, Koelewijn JM, van der Schoot CE. Haemolytic disease of the fetus and newborn. Vox Sang. 2015;109 (2):99-113. doi:10.1111/vox.12265

2. Ma X, Chen FZ, Hong Q. [Analysis of screening results in 501 newborns with hemolytic disease]. Zhongguo Shi Yan Xue Ye Xue Za Zhi. 2019;27(1):192-196. Chinese. doi:10.7534/j.issn.10092137.2019.01.031

3. Doyle B, Quigley J, Lambert M, et al. A correlation between severe haemolytic disease of the fetus and newborn and maternal ABO blood group. Transfus Med. 2014;24(4):239-243. doi:10.1111/ tme.12132

4. Herschel M, Karrison T, Wen M, Caldarelli L, Baron B. Isoimmunization is unlikely to be the cause of hemolysis in ABO-incompatible but direct antiglobulin test-negative neonates. Pediatrics. 2002;110(1 Pt 1):127-130.

5. Rath ME, Smits-Wintjens VE, Lindenburg IT, et al. Postnatal outcome in neonates with severe Rhesus c compared to rhesus D hemolytic disease. Transfusion. 2013;53(7):1580-1585. doi:10.1111/j.1537-2995.2012.03937.x

6. Tewari VV, Kumar A, Singhal A, et al. Evaluation of Rh-Hemolytic disease in neonates and management with early intensive phototherapy in the neonatal intensive care unit. J Trop Pediatr. 2020;66 (1):75-84. doi:10.1093/tropej/fmz033

7. Altunyurt S, Okyay E, Saatli B, Canbahishov T, Demir N, Ozkan H. Neonatal outcome of fetuses receiving intrauterine transfusion for severe hydrops complicated by Rhesus hemolytic disease. Int J Gynaecol Obstet. 2012;117(2):153-156. doi:10.1016/j. ijgo.2011.12.013

8. Koelewijn JM, Vrijkotte TG, van der Schoot CE, Bonsel GJ, de Haas M. Effect of screening for red cell antibodies, other than anti-D, to detect hemolytic disease of the fetus and newborn: a population study in the Netherlands. Transfusion. 2008;48 (5):941-952.

9. Katsuragi S, Ohto H, Yoshida A, et al. Anemic disease of the newborn with little increase in hemolysis and erythropoiesis due to maternal anti-Jr(a): a Case Study and Review of the Literature. TRANSFUS MED REV. 2019;33(3):183-188. doi:10.1016/j. tmrv.2019.03.002

10. Gu S, Wang HX, Yang CY, et al. [Clinical analysis of seven cases of rare hemolytic disease of the newborn]. Zhonghua $\mathrm{Er} \mathrm{Ke} \mathrm{Za} \mathrm{Zhi.}$ 2018;56(5):369-372. Chinese. doi:10.3760/cma.j.issn.05781310.2018 .05 .012

11. Wei CT, Al-Hassan FM, Naim N, Knight A, Joshi SR. Prevalence of Diego blood group antigen and the antibody in three ethnic population groups in Klang valley of Malaysia. Asian J Transfus Sci. 2013;7 (1):26-28. doi:10.4103/0973-6247.106725

12. Bakhtary S, Gikas A, Glader B, Andrews J. Anti-Mur as the most likely cause of mild hemolytic disease of the newborn. Transfusion. 2016;56(5):1182-1184. doi:10.1111/trf.13552

13. Weiner CP, Widness JA. Decreased fetal erythropoiesis and hemolysis in Kell hemolytic anemia. Am J Obstet Gynecol. 1996;174 (2):547-551. doi:10.1016/S0002-9378(96)70425-8 
14. Management of hyperbilirubinemia in the newborn infant. 35 or more weeks of gestation. Pediatrics. 2004;114(1):297-316. doi:10.1542/ peds.114.1.297

15. Mari G, Deter RL, Carpenter RL, et al. Noninvasive diagnosis by Doppler ultrasonography of fetal anemia due to maternal red-cell alloimmunization. Collaborative group for Doppler assessment of the blood velocity in anemic fetuses. $N$ Engl J Med. 2000;342 (1):9-14. doi:10.1056/NEJM200001063420102

16. Markham KB, Rossi KQ, Nagaraja HN, O’Shaughnessy RW. Hemolytic disease of the fetus and newborn due to multiple maternal antibodies. Am J Obstet Gynecol. 2015;213(1):61-68. doi:10.1016/j. ajog.2015.01.049

17. Yang ZYST. The value of antibody screening test during antenatal clinic to prevent HDN. Attachment of one case with anti-M neonatal hemolysis disease. Chin J Immunol. 2017;2(33):278-279.

18. Christensen RD, Baer VL, MacQueen BC, O’Brien EA, Ilstrup SJ. ABO hemolytic disease of the fetus and newborn: thirteen years of data after implementing a universal bilirubin screening and management program. J PERINATOL. 2018;38(5):517-525. doi:10.1038/ s41372-018-0048-4

19. Louis D, More K, Oberoi S, Shah PS. Intravenous immunoglobulin in isoimmune haemolytic disease of newborn: an updated systematic review and meta-analysis. Arch Dis Child Fetal Neonatal Ed. 2014;99(4):F325-31. doi:10.1136/archdischild-2013-304878

20. Christensen RD, Yaish HM. Hemolysis in preterm neonates. Clin Perinatol. 2016;43(2):233-240. doi:10.1016/j.clp.2016.01.002

21. Moise KJ. Non-anti-D antibodies in red-cell alloimmunization. Eur J Obstet Gynecol Reprod Biol. 2000;92(1):75-81. doi:10.1016/ S0301-2115(00)00428-0

22. Lee CK, Ma ES, Tang M, Lam CC, Lin CK, Chan LC. Prevalence and specificity of clinically significant red cell alloantibodies in Chinese women during pregnancy-a review of cases from 1997 to 2001. Transfus Med. 2003;13(4):227-231. doi:10.1046/j.13653148.2003.00445.x

23. Castilho L. An update on the MNS blood group system. Immunohematology. 2019;35(2):61-62. doi:10.21307/immunohematology-2020-014

24. Slootweg YM, Walg C, Koelewijn JM, Van Kamp IL, De Haas M. Knowledge, attitude and practices of obstetric care providers towards maternal red-blood-cell immunization during pregnancy. Vox Sang. 2020;115(3):211-220. doi:10.1111/vox.12883

25. Reid ME. MNS blood group system: a review. Immunohematology. 2009;25(3):95-101.

26. De Young-owens A, Kennedy M, Rose RL, Boyle J, O'Shaughnessy R. Anti-M isoimmunization: management and outcome at the Ohio State University from 1969 to 1995. Obstet Gynecol. 1997;90(6):962-966. doi:10.1016/S0029-7844(97)00476-6
27. Hassan MN, Mohd NN, Johan NS, Sukri SA, Mustafa R, Luc AH. Hemolytic disease of fetus and newborn due to maternal red blood cell alloantibodies in the Malay population. Asian J Transfus Sci. 2014;8(2):113-117. doi:10.4103/0973-6247.137449

28. Li S, Mo C, Huang L, et al. Hemolytic disease of the fetus and newborn due to alloanti-M: three Chinese case reports and a review of the literature. Transfusion. 2019;59(1):385-395. doi:10.1111/ trf. 15054

29. Stetson B, Scrape S, Markham KB. Anti-M alloimmunization: management and outcome at a single institution. AJP Rep. 2017;7(4): e205-10. doi:10.1055/s-0037-1607028

30. Mohd NH, Noor HM, Shafini MY, Noor SAA, Rapiaah M, Wan ZA. Anti-M induced severe haemolytic disease of foetus and newborn in a Malay woman with recurrent pregnancy loss. Malays J Pathol. 2017;39(1):73-76.

31. Yasuda H, Ohto H, Nollet KE, et al. Hemolytic disease of the fetus and newborn with late-onset anemia due to anti-M: a case report and review of the Japanese literature. Transfus Med Rev. 2014;28(1):1-6. doi:10.1016/j.tmrv.2013.10.002

32. Gao XY, Huang H, Li LD. [Hemolytic disease of neonates due to anti-M: report of one case and review of reports of 21 cases]. Zhonghua Er Ke Za Zhi. 2009;47(9):648-652. Chinese.

33. Arora S, Doda V, Maria A, Kotwal U, Goyal S. Maternal anti-M induced hemolytic disease of newborn followed by prolonged anemia in newborn twins. Asian J Transfus Sci. 2015;9(1):98-101. doi:10.4103/0973-6247.150968

34. Wikman A, Edner A, Gryfelt G, Jonsson B, Henter JI. Fetal hemolytic anemia and intrauterine death caused by anti-M immunization. Transfusion. 2007;47(5):911-917. doi:10.1111/j.15372995.2007.01209.x

35. Lenkiewicz B, Zupanska B. The first example of anti-Diego(b) found in a Polish woman with the $\operatorname{Di}(\mathrm{a}+\mathrm{b}-)$ phenotype and haemolytic disease of the newborn not requiring treatment. Transfus Med. 2003;13(3):161-163. doi:10.1046/j.1365-3148.2003.00437.x

36. Oh EJ, Jekarl DW, Jang HS, et al. Severe hemolytic disease of the newborn due to anti-Di b treated with phototherapy and intravenous immunoglobulin. Ann Clin Lab Sci. 2008;38(1):80-82.

37. Hamilton JR. Kidd blood group system: a review. Immunohematology. 2015;31(1):29-35.

38. Lawicki S, Covin RB, Powers AA. The Kidd (JK) Blood Group System. Transfus Med Rev. 2017;31(3):165-172. doi:10.1016/j. tmrv.2016.10.003
Journal of Blood Medicine

\section{Publish your work in this journal}

The Journal of Blood Medicine is an international, peer-reviewed, open access, online journal publishing laboratory, experimental and clinical aspects of all aspect pertaining to blood based medicine including but not limited to: Transfusion Medicine; Blood collection, Donor issues, Transmittable diseases, and Blood banking logistics; Immunohematology; Artificial and alternative blood based therapeutics; Hematology; Biotechnology/nanotechnology of blood related medicine; Legal aspects of blood medicine; Historical perspectives. The manuscript management system is completely online and includes a very quick and fair peer-review system. Visit http://www.dovepress.com/testimonials.php to read real quotes from published authors. 